\section{A EDUCAÇ̃̃O DE JOVENS E ADULTOS PAUTADA NA CIDADANIA E NA CONSTRUÇÃO DO SUJEITO SOCIAL: UM ESTUDO DE CASO NAS ESCOLAS ESTADUAIS PROFESSOR NELSON BARROS E BATISTA NEVES}

\author{
EDUCACIÓN DE ADULTOS BASADA EN LA CIUDADANÍA Y LA CONSTRUCCIÓN \\ DE LA PERSONA SOCIAL: UN ESTUDIO DE CASO EN LAS ESCUELAS ESTATALES \\ PROFESOR NELSON BARROS Y BATISTA NEVES
}

\author{
ADULT EDUCATION BASED ON CITIZENSHIP AND THE CONSTRUCTION OF \\ THE SOCIAL PEOPLE: A CASE STUDY AT STATE SCHOOLS PROFESSOR NELSON \\ BARROS AND BATISTA NEVES
}

RESUMO: Este artigo disserta sobre a construção do ser social e a formação cidadã dentro da Educação de Jovens e Adultos, em um estudo de caso com alunos do Colégio Estadual Professor Nelson Barros e do Colégio Estadual Batista Neves, ambos em Salvador. É uma pesquisa de abordagem qualitativa que visa analisar em conjunto com as perspectivas vygotskyanas e as contribuições de autores como Bakhtin, Freire e Santos como a EJA impacta nas histórias de vida dessas pessoas e na sua construção social. Os resultados deste estudo demonstraram que, por mais que a EJA desempenhe a ação de reparação do direito à educação para todos, as práticas pedagógicas não obtêm resultados equânimes nas escolas, proporcionando ao aluno o acesso à informação, mas não promovendo entre estes uma abordagem que fomente a cidadania enquanto práxis.

PALAVRAS-CHAVE: Educação de jovens e adultos. Cidadania. Socioconstrutivismo. Espaços do cidadão.

RESUMEN: Este artículo tiene como objetivo discutir la construcción del ser social, de la formación ciudadana dentro de la Educación de Adultos, en un estudio de caso con estudiantes del Colegio Estatal Profesor Nelson Barros y del Colegio Estatal Batista Neves, ambos en la ciudad de Salvador. Es una investigación con un enfoque cualitativo que tiene como objetivo analizar junto con las perspectivas vygotskianas y las contribuciones de autores como Bakhtin, Paulo Freire y Milton Santos sobre cómo la Educación de Adultos impacta en las historias de vida de estas personas y en su construcción social. Los resultados de este estudio demostraron

${ }^{1}$ Universidade do Estado da Bahia (UNEB), Salvador - BA - Brasil. Mestrando no Programa de Pós-Graduação em Educação de Jovens e Adultos. ORCID: http://orcid.org/0000-0002-7627-3318. E-mail: fabiopereira91@gmail.com

${ }^{2}$ Universidade do Estado da Bahia (UNEB), Salvador - BA - Brasil. Professor no Programa de Pós-Graduação em Difusão do Conhecimento no Programa de Pós-Graduação em Educação e Contemporaneidades. Doutorado em Educação (UFBA). ORCID: https://orcid.org/0000-0002-7715-0918. E-mail: alfredo@matta.pro.br

${ }^{3}$ Universidade do Estado da Bahia (UNEB), Salvador - BA - Brasil. Professor Titular Pleno nos cursos de Graduação e de Pós-Graduação. Pós-Doutorado em Difusão do Conhecimento (UNEB). ORCID: https://orcid.org/0000-0003-3236-9139. E-mail: antonioamorim52@gmail.com 
que a pesar de que la Educación de Adultos realiza la acción de reparar el derecho a la educación para todos, las prácticas pedagógicas no obtienen resultados equitativos en las escuelas, proporcionando a los estudiantes acceso a la información, pero no promoviendo entre ellos un enfoque que promueva la ciudadanía como praxis.

PALABRAS CLAVE: Educación de jóvenes y adultos. Ciudadanía. Socioconstructivismo. Espacios ciudadanos.

ABSTRACT: This article aims to discuss the construction of social people, of citizen formation within Adult Education, in a case study with students from the State College Professor Nelson Barros and State College Batista Neves both in Salvador city. It is a qualitative research that target at analyze together with the Vygotskian perspectives and the contributions of authors such as Bakhtin, Freire and Santos of how the Adult Education impacts on these people's life stories and on their social construction. The results of this study demonstrated that even though Adult Education performs the action of repairing the education law for all, pedagogical practices do not obtain equitable results in schools, providing students with access to information, but not promoting among citizenship as praxis.

KEYWORDS: Youth and adult education. Citizenship. Socioconstructivism. Citizen spaces.

\section{INTRODUÇÃO}

O presente artigo disserta sobre a construção da cidadania do ser social dentro da Educação de Jovens e Adultos, e tem como principal destaque de análise o entendimento por parte dos estudantes sobre a cidadania e a sua ótica sobre como a educação no chão da sala de aula vem colaborando (ou não) na construção dos seus múltiplos papéis na sociedade.

Promover a discussão e a correlação entre esses dois eixos temáticos (Cidadania e a EJA) torna-se oportuno tanto pelo contexto social em que os estudantes vivem, como pela própria situação de vulnerabilidade que esta modalidade educacional se encontra na contemporaneidade brasileira. Discutir a sua importância perpassa pelas questões formativas da educação, a busca pela erradicação do analfabetismo e o aumento do tempo de estudo do brasileiro, o que evidencia a relevância consubstancial nas problemáticas sociais que as classes desabastadas e os grupos minoritários sofrem cotidianamente.

Dentro da EJA há uma heterogeneidade que nos remete a um questionamento: Como as histórias de vida daqueles sujeitos impactam no seu processo de aprendizagem? E o principal destas discussões: como a EJA impacta nas histórias de vida destas pessoas e no seu protagonismo (ou no seu "não protagonismo") social? 
O cenário conturbado que a educação brasileira vive no final da segunda década do século XXI, cuja ações governamentais têm realizado mudanças que põem em dúvida a sobrevivência da EJA, evidencia grandes revezes, como a dissolução de Secretarias e Comissões. Estudar esta temática visa demonstrar o quão importante são as ações da EJA para o enfrentamento das questões que agravam ainda mais as desigualdades sociais e a reivindicação do "ser cidadão" por estas pessoas, que há anos são marginalizadas e negligenciadas pela sociedade.

Para alicerçar este estudo sobre a cidadania na EJA e elucidar as questões sobre a problemática apresentada, entendemos como objetivo geral deste artigo analisar de que maneira as práticas pedagógicas contribuem na construção do sujeito social em seus alunos e, diante deste contexto, procuram buscar respostas para as principais indagações. Determinamos como objetivos específicos deste artigo as correlações entre a cidadania e o espaço do cidadão na visão de Milton Santos, com o entendimento de cidadania destes sujeitos, e como a sociabilização entre os alunos e docentes no chão da sala de aula da EJA contribui na sua criticidade social e política.

Este artigo organiza-se por esta introdução, na qual destacamos a temática e consequentemente as suas problemáticas e justificativas que fundamentam este estudo e os seus objetivos. $\mathrm{O}$ delineamento metodológico que nos permitiu realizar a análise necessária para o aprofundamento desta temática e o entendimento da realidade baseiam-se na pesquisa qualitativa, com uma abordagem em um estudo de caso múltiplo, ouvindo os estudantes dos Colégios Estaduais Professor Nelson Barros, no bairro de Cajazeiras X e o Batista Neves, no bairro de Cajazeiras V, em Salvador.

Para a fundamentação teórica deste trabalho, foram utilizadas a abordagem socioconstrutivista e a teoria da psicologia social de Lev Vygotsky, em conjunto com os estudos de identidade e polifonia de Bakhtin, auxiliando a estabelecer ligações entre os estudantes da EJA com as suas problematizações, com o processo de aprendizado e suas relações sociais. Sobre este último, os estudos de Milton Santos e Paulo Freire também dão o suporte necessário para transversalizar a EJA com a temática da cidadania. Por fim, dissertamos sobre os sujeitos participantes, o seu local de socialização escolar, os instrumentos utilizados para a observação da temática estudada neste artigo na sala de aula, os resultados obtidos desta investigação e as referências utilizadas neste estudo. 


\section{Procedimentos metodológicos da investigação}

Para esta pesquisa, utilizamos uma abordagem qualitativa com uma abordagem de levantamento e análise pautada no estudo de caso múltiplo. Este tipo de pesquisa nos possibilitou a observação de novos questionamentos e contextos sociais, nos quais as "metodologias tradicionais" não conseguem dialogar, e isto nos impulsionou ao estudo qualitativo, já que ele “[...] é de particular relevância ao estudo das relações sociais devido à pluralização das esferas de vida" (FLICK, 2017, p. 20), sendo este justamente o cenário que encontramos na sala de aula da Educação de Jovens e Adultos.

A pesquisa qualitativa oferece mecanismos que nos auxiliam na elaboração de hipóteses e respostas dos questionamentos visíveis (e invisíveis) do universo antropológico, trabalhando com elementos nos quais o método quantitativo não mensura com tamanha destreza, já que há neste processo um "[...] universo dos significados, dos motivos, das aspirações, das crenças, dos valores e das atitudes" (MINAYO, 2016 p. 21-22). Todo este "universo" se relaciona simbioticamente com a realidade do sujeito, haja vista que o homem age, mas por ser consciente ele pensa, interpreta e conceitua qualquer tipo de ação, e todo este processo precisa ser analisado e entendido.

Para além de dados e tabulações, a pesquisa qualitativa proporcionou neste trabalho a possibilidade de mensurar os aspectos subjetivos que estão presentes dentro da relação entre cidadania, EJA e os sujeitos que a frequentam. Esta correlação de saberes sobre a temática entre o pesquisador e os sujeitos partícipes, além de ser uma das características necessárias para a construção do conhecimento sobre Cidadania e EJA, ao mesmo tempo é um dos princípios da pesquisa qualitativa, na qual o reconhecimento da singularidade do sujeito e do seu modo de viver nos possibilitam entender a sua realidade social.

Para consubstanciar o processo investigativo deste artigo através do estudo de caso, trouxemos de maneira referencial as produções de Yin (2014) e de Gil (2010) acerca dos estudos de casos (simples e múltiplos), fundamentalizados pelo entendimento e a aplicação deste dispositivo estratégico, que vem sendo utilizado amplamente para os estudos na área de pesquisa social, já que este tem por característica atender a diversos propósitos; dentre eles, Gil (2010, p. 58) destaca:

a) explorar situações da vida real cujos limites não estão claramente definidos; b) descrever a situação do contexto em que está sendo feita determinada investigação; e

c) explicar as variáveis causais de determinado fenômeno em situações muito complexas que não possibilitam a utilização de levantamentos e experimentos. 
Yin (2017, p. 32) define o estudo de caso como "[...] uma investigação empírica que investiga um fenômeno contemporâneo dentro do seu contexto da vida real, especialmente quando os limites entre o fenômeno e o contexto não estão claramente definidos". Traçando um paralelo entre a conceituação de Yin sobre o estudo de caso com os propósitos elencados por Gil, ambos pavimentam a sua aplicabilidade entre os sujeitos da EJA na busca de debatermos sobre a formação cidadã destes durante o seu processo de formação na sala de aula, haja vista que temos dentro deste espaço pessoas com histórias de vida totalmente diferentes umas das outras, além das variantes sociais e educacionais que a contemporaneidade proporciona e que influenciam todo o processo formativo dos estudantes enquanto seres sociais e cidadãos.

Para este trabalho, utilizaremos o projeto de caso múltiplos holísticos, pois o seu fundamento lógico está em observar uma única unidade de análise em múltiplos casos, o que se encaixa com o objeto de estudo deste artigo, o qual consiste em analisar os estudantes da EJA do Colégio Estadual Professor Nelson Barros e do Batista Neves, já que apesar da heterogeneidade do público, a criação de subunidades entre os sujeitos envolvidos não seria relevante para a temática pesquisada. O Colégio Estadual Professor Nelson Barros situa-se no bairro de Cajazeiras 10, que conta com aproximadamente $8.513^{4}$ moradores. Neste colégio, selecionamos 20 estudantes da EJA do turno noturno das turmas de $1^{\circ} \mathrm{e} 2^{\circ}$ ano para participarem do estudo de caso. O Colégio Estadual Batista Neves, localizado na Estrada do Matadouro, dentro do bairro Cajazeiras 5, busca atender a demanda de uma região com 5.422 moradores. Na modalidade da EJA, disponibilizada nos turnos vespertino e noturno, foram selecionados 20 estudantes do turno vespertino da turma de Tempo Juvenil para o estudo de caso deste artigo. Mesmo inseridas em dois diferentes bairros, ambas compartilham a mesma história de desenvolvimento e também de problemáticas urbanas e sociais.

Como instrumentalização para o levantamento e coleta de dados com os sujeitos envolvidos no estudo, optamos por realizar entrevistas usando um questionário semiestruturado, pois segundo Triviños (2009), a entrevista semiestrurada, quando correlacionada com as teorias e hipóteses já elencadas e observadas pelo pesquisador, tem por efeito, após a sua aplicação, a verificação de novas perspectivas de hipóteses a partir das respostas dos entrevistados, haja vista que mesmo dissertando sobre temas comuns a todos, a possibilidade de colher respostas mais livres de cada entrevistado nos permite entender como o contexto e as relações de um determinado sujeito influenciam totalmente em suas convicções, opiniões e em sua visão de mundo.

${ }^{4}$ Segundo o CENSO 2010, disponibilizado também no Painel de Informações INFORMS da CONDER. 
Esta pesquisa, portanto, após o entendimento acerca da metodologia, dispositivos estratégicos e instrumentação utilizada para o processo de estudo, prossegue com o aprofundamento teórico da temática em conjunto com as obras de Lev Vygotsky sobre a teoria socio-histórica de Mikhail Bakhtin acerca de identidade e polifonia, como também os trabalhos de Milton Santos e Paulo Freire sobre o espaço do cidadão, cidadania e educação problematizadora, que dão toda a estruturação necessária para o debate e o levantamento de hipóteses que serão observados em campo com o processo de entrevista e, posteriormente, com a análise desses relatos embasados com a etapa a seguir, que nos permite chegar aos objetivos citados no início deste trabalho.

\section{EJA como espaço do aluno: um ser social e cidadão}

Presente no item 2 do artigo primeiro da Constituição da República Federativa do Brasil, a cidadania é um dos pilares que fundamentam o Estado Democrático de Direito do país, e a educação é elencada como um dos principais vetores para o exercício da própria cidadania, em conjunto com o desenvolvimento humano e a qualificação do indivíduo para o trabalho (BRASIL, 2017). A aplicação da terminologia dentro da Carta Magna relaciona-se ao exercício da nacionalidade brasileira, sem trazer um sentido mais amplo, já Houaiss (2015, p. 211) define cidadania como: "1. qualidade ou condição de cidadão, [...] 2. condição de pessoa que, como membro de um Estado, se acha no gozo de direitos que lhe permitem participar da vida política", e esta condição está subordinada justamente à capacidade do Estado de fornecer aos indivíduos os seus direitos sociais, possibilitando a sua plena participação na vida política (partindo do seu conceito etimológico como o sujeito da Pólis).

Contudo, o não cumprimento pleno dos direitos sociais por parte do Estado e o histórico perfil de negligência e opressão às classes mais vulneráveis da sociedade brasileira transformaram a visão sobre cidadania em um princípio utópico para as minorias e também como um atributo pertencente somente às elites sociais do país. Essa relação socioeconômica dos indivíduos com a capacidade de participar das tomadas de decisão da sociedade e no usufruto dos seus direitos proporcionou à cidadania uma condição de ser conquistada e mediada pelo capital, retirando dela o seu princípio de igualdade.

A desvirtuação da cidadania atualmente é legitimada pelo Estado, com a erradicação das Secretarias e Instituições que justamente buscavam garantir aos indivíduos (principalmente os de classes sociais mais vulneráveis) o cumprimento dos seus direitos sociais, com uma estratégia paradoxal à função do Estado, que adota uma postura de que o brasileiro "prefere ter 
menos direitos para obter emprego", Couto (2019, p. 01), em 100 dias de governo iniciado em 2019, com os obstáculos que antes já atingiam a modalidade de ensino, como a desatualização dos materiais didáticos para o público, novos problemas surgem quando a EJA não é incluída no desenho da Política Nacional de Alfabetização, tendo as atividades da SECADI e da CNAEJA encerradas. Isto afeta tanto o processo qualitativo de formação dos sujeitos matriculados, como também desmonta a função de reparação social presente na EJA, seja dentro da sala de aula, seja nas articulações da sociedade civil e dos movimentos sociais com o governo.

Para Bakhtin (2017, p. 132), através da fala é possível verificar as diferentes "vozes" que se apresentam dentro de um enunciado, demonstrando em uma oração as diversas vivências que aquele sujeito construiu ao longo de sua vida e, neste aspecto, o filosofo sugere que a "[...] cada palavra da enunciação que estamos em processo de compreender, fazemos corresponder uma série de palavras nossas, formando uma réplica. Quanto mais numerosas e substanciais forem, mais profunda e real é a nossa compreensão". Dentro do contexto da EJA, os sujeitos ali presentes trazem complexidades e "vozes" que são latentes no seu processo de interação e aprendizado. As ações docentes e toda a estrutura curricular escolar devem abarcar esta peculiaridade, pois esses "tensionamentos" presentes na vida destes estudantes também estão dentro do ambiente escolar e, quando não se promove a dialogicidade dos conteúdos e da prática pedagógica com estes sujeitos, isto se torna um grande problema.

Em um cenário no qual muitos dos alunos são trabalhadores, pais e mães de famílias e egressos buscam através da educação ferramentas para saber lidar com as suas dificuldades e consequentemente capacitarem-se; a estrutura pedagógica deve pautar-se na capacidade de correlação do conteúdo formativo com o cotidiano destes indivíduos, fomentando a problematização, a criticidade e incentivando o protagonismo dos estudantes nas tomadas de decisões. Para isto, Freire (2019, p. 119) sugere uma mudança na ação do docente dentro da sala de aula, destacando que:

[...] o educador problematizador refaz, constantemente, seu ato cognoscente, na cognoscibilidade dos educandos. Estes, em lugar de serem recipientes dóceis de depósitos, são agora investigadores críticos, em diálogo com o educador, investigador crítico também.

${ }^{5}$ Mensagem extraída da entrevista do presidente Jair Bolsonaro no periódico Carta Capital. Disponível em: https://www.cartacapital.com.br/politica/os-trabalhadores-querem-menos-direitos-e-mais-trabalho-dizbolsonaro/. Acesso em: 10 out. 2020. 
Buscar enxergar os sujeitos que estão por trás dos alunos faz do ato de educar, em cada sala, um ato único e abrangente, pois traz na ação de difusão do conhecimento os saberes destes sujeitos que foram moldados pela sua história, sua cultura, sua ancestralidade, sua regionalidade, e partindo do princípio que a escola também é uma instituição de desenvolvimento social de um bairro, de sua cidade, ela deve desempenhar o papel de elucidação das problemáticas sociais destes espaços através do ensino.

Nisto, percebemos que a escola tende a ser um espaço de cidadania, no qual os sujeitos presentes dentro da instituição tanto vivenciam o ser cidadão (de maneira consciente e inconsciente), quanto devem fomentar o debate sobre cidadania dentro da escola e fora dela, pois apesar de todos nascerem cidadãos, plenos de poderem gozar dos seus direitos, a cidadania é um estado de espírito que se aprende e se conquista constantemente através do diálogo entre os indivíduos sobre sua cultura, história e participação social e política (SANTOS, 2014).

Mesmo havendo dentro do cenário político brasileiro o processo de desvalorização e ojeriza da obra de Paulo Freire, as suas contribuições para a Educação Popular e a sua proposta de prática pedagógica pautada na dialética e no protagonismo dos sujeitos torna-se ainda mais fundamental dentro da EJA. Efetivar o debate e a construção sobre o ser social no processo de ensino/aprendizagem, com o entendimento de que a educação deve ter um posicionamento político que promova a liberdade das pessoas, é uma consequência lógica de uma proposta educativa que visa conscientizar os estudantes, pois proporcionar a estes o comando do seu processo histórico-cultural é induzi-los à conscientização da sua vida, do seu papel social, sendo que conscientizar é politizar (FREIRE, 2019).

Logo, a fomentação do debate sobre o sujeito social e como nós (docentes, discentes e demais membros da escola) podemos reivindicar o nosso espaço de cidadão, exercendo o protagonismo político, comunitário e social, tem a escola como o principal espaço para a estimulação deste "estado de espírito" da cidadania, uma vez que a sala de aula dispõe de elementos fundantes para isto: o docente como mediador do processo de ensino/aprendizagem e os discentes na ação de interação entre si e o professor, correlacionando o aprendizado com o seu contexto de vida e as suas relações sociais. Por isso, Vygotsky $(2015$, p. 105) afirma sobre a importância da interação socio-histórica entre os indivíduos para o seu desenvolvimento, pois:

O desenvolvimento humano passa, necessariamente pelo outro, portanto, a história de cada uma das funções psíquicas é uma história social. Por isso poderíamos dizer que é por meio dos outros que nos tornamos nós mesmos e esta regra se aplica não só ao indivíduo como um todo, mas também a história de cada função separadamente. 
Portanto, se a formação cidadã é um processo construtivo de um estado de espírito e cultural, a educação se torna a pedra angular no processo de conscientização dos indivíduos como cidadãos, transcendendo do "Ser Passivo" da sociedade, que só possui direitos e deveres, nos quais eles sequer participaram para a legitimação de si mesmos, para o "Ser Ativo" socialmente, ciente da sua participação política e comunitária nas tomadas de decisão da sua própria vida e da sociedade como um todo.

\section{Resultados encontrados}

Como parte do processo de desenvolvimento desta pesquisa sobre como as práticas pedagógicas na EJA têm contribuído para a construção do ser social e do debate acerca da cidadania, realizamos dois encontros durante o mês de novembro de 2019 nas Escolas Estaduais Professor Nelson Barros e Batista Neves. Estes momentos foram registrados em um questionário e por meio de entrevista. Em seguida, foram analisados a fim de constatarmos o processo de ensino/aprendizagem e as relações entre professores e alunos no chão da sala destas instituições, que têm promovido o impacto na vida destes estudantes na sua formação cidadã.

As entrevistas realizadas com os alunos foram iniciadas com a pergunta norteadora da temática desta pesquisa: o que é cidadania? Disto, destacamos o comentário de uma aluna sobre a sua visão de cidadania: "Pergunta: O que é Cidadania para vocês? Resposta: É você poder participar dos deveres do Estado, contribuir com as atividades de sua cidade, meio ambiente etc... “ (P5 - 30 anos - E.E. Batista Neves, 2019)

A visão de um "Ser Ativo" no exercício da cidadania está associada à fala da aluna entrevistada quando ela traz a cidadania como práxis do indivíduo, o qual é protagonista nas tomadas de decisão, indo ao encontro do estudo de Santos (2014, p. 20) ao afirmar que a “"...] cidadania sem dúvida, sem aprende. É assim que ela se torna um estado de espírito, enraizado na cultura", e a educação deve promover concomitantemente à prática pedagógica e ao conteúdo didático a percepção destes sujeitos como agentes da cidadania em seus espaços de vivência.

Durante a entrevista, questionamos se os assuntos ministrados em sala de aula pelos professores influenciavam o interesse dos alunos sobre política, na sua participação social e em sua autonomia. Ao final de cada entrevista, perguntamos aos indivíduos sobre a importância que a convivência em sala de aula tem, influenciando as suas vidas e mostrando a eles um quadro com objetivos que a EJA pode lhes proporcionar e, além disso, solicitamos que cada um deles selecionasse três opções. Tudo isso nos permitiu observar, além do entendimento sobre a 
formação cidadã destes sujeitos, a maneira que eles enxergam sua construção enquanto seres sociais.

$\mathrm{Na}$ Escola Nelson Barros, a turma avaliada possui um perfil amplamente masculino e jovem (com uma faixa etária que vai dos 15 até os 45 anos). Ao discutir sobre cidadania, muitos afirmam ter direitos e deveres, mas ao aprofundarmos o diálogo visando entender como os conteúdos dados na escola os afetam ou os influenciam no exercício da cidadania, $80 \%$ (juntando os dados de "Pouca influência" e "Nenhuma Influência", conforme demonstra o gráfico abaixo) dos alunos não correlacionam os conteúdos como base de formação em suas decisões políticas, enquanto $20 \%$ (em conjunto com as respostas de "Bastante influência" e Total influência") estabelecem conexões do conteúdo obtido com a sua formação/engajamento político. Assim, 55\% afirmaram que os estudos não influenciam em seu engajamento comunitário e nas suas relações familiares, em face dos $45 \%$ dos estudantes que concordaram que a convivência com os demais colegas e professores, em conjunto com o aprendizado, tem reverberado na sua postura referente às questões e problematizações presentes em sua comunidade.

Gráfico 1 - Relação dos estudos com a participação política e social - Escola Nelson Barros

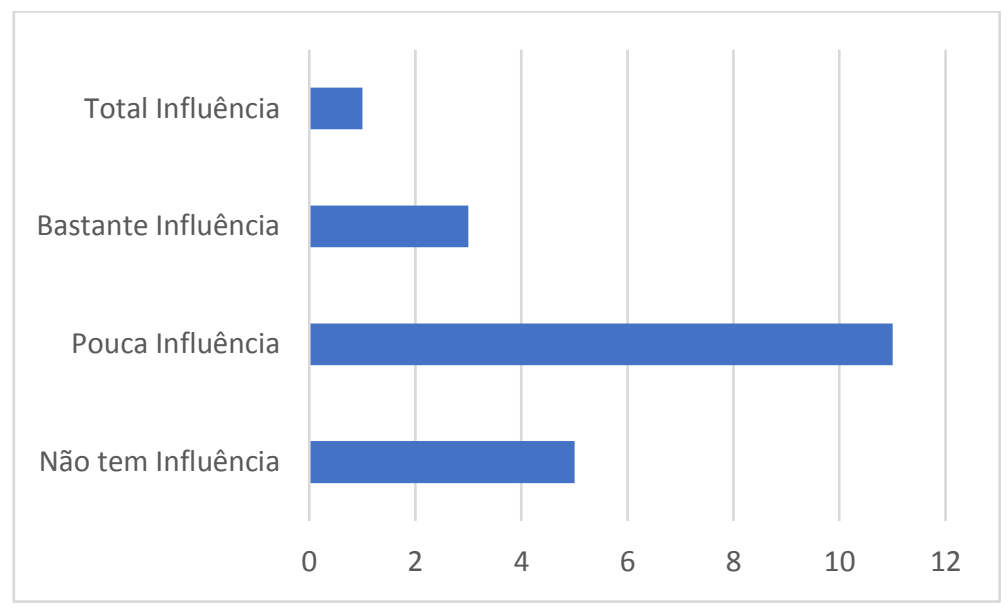

Fonte: Elaborado pelos pesquisadores

A alta porcentagem dos estudantes afirmando que a escola não influencia nas suas decisões políticas e na sua participação comunitária é resultado de uma dissociação dos saberes adquiridos na escola com o exercício da cidadania, e até mesmo da visão do papel da escola no desenvolvimento do protagonismo social destes sujeitos. Com isso, vale ressaltar a necessidade da atuação que o professor tem com os seus alunos para além do conteúdo didático, pois Paulo Freire (2019, p. 103) em Pedagogia da Autonomia retrata que: 
Assim como não posso ser professor sem me achar capacitado para ensinar certo e bem os conteúdos de minha disciplina, não posso, por outro lado, reduzir minha prática docente ao puro ensino daqueles conteúdos. [...] Tão importante quanto o ensino dos conteúdos é minha coerência em classe.

Observamos, conforme a explicação do educador Paulo Freire, que a ação docente no chão da sala de aula deve ser um processo constante de observação por parte do educador no que se refere ao entendimento do aluno sobre como o conteúdo debatido em sala reflete em sua vivência e no seu desenvolvimento.

Figura 1 - Nuvem de palavras dos aspectos mais importantes - Escola Nelson Barros

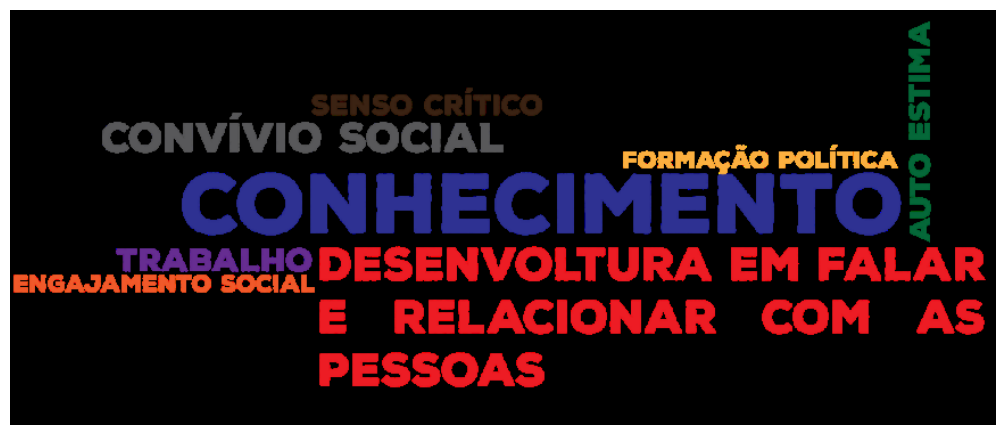

Fonte: Elaborado pelos pesquisadores

Prosseguindo com as informações obtidas no estudo de caso, para a maioria dos alunos avaliados da Escola Estadual Nelson Barros, a EJA (tanto como ambiente de aprendizado, quanto espaço de convivência) não trouxe um impacto para estes sujeitos para além do aspecto formativo, pois o conteúdo não tem sido capaz de propor uma correlação com as suas problemáticas sociais e isto se torna evidente tanto na nuvem de palavras, desenvolvida com as respostas sobre os aspectos mais benéficos que a EJA promove, girando em torno majoritariamente do conhecimento e da comunicação interpessoal, quanto na fala dos alunos sobre a contribuição para a sua vida:

Melhorou muito! Eu aprendi muita coisa que eu vou levar para o resto da vida. Hoje em dia, sempre precisa da educação para os jovens e adultos terem o conhecimento. Nos dedicamos melhor, aprendemos a respeitar os professores. (P14 - 16 anos - E.E. Nelson Barros, 2019)

A importância da comunicação por parte dos alunos participantes da Escola Estadual Professor Nelson Barros confirma uma característica que Vygotsky retrata como fundamental para o desenvolvimento humano: as relações socio-históricas, já que a comunicabilidade e a troca de visões de mundo por parte dos estudantes (que em diversos casos dividem os mesmos 
tensionamentos sociais) possibilitam a construção coletiva de saberes que podem ser fundamentais para o desenvolvimento individual e comunitário, podendo também ser aglutinados na escola, incentivando os estudantes tanto na percepção das problemáticas que os afetam socialmente, quanto no protagonismo das soluções enquanto cidadãos.

$\mathrm{Na}$ Escola Estadual Batista Neves, que possui um perfil bastante heterogêneo e com maior presença feminina (com $45 \%$ do público entrevistado, tendo $40 \%$ de estudantes masculinos e destacando também na turma avaliada a presença de $15 \%$ que declararam a opção "Outros"), a discussão inicial sobre cidadania abordou questões que envolvem tanto o protagonismo dos indivíduos na melhoria social e urbana da cidade como alguns pontos de discussão sobre os direitos e deveres, conforme as respostas a seguir:

Cidadania é um ser que cumpre todos os seus deveres como cidadão: votar, pagar seus impostos, se alistar no exército e na sociedade procurar ser sempre um homem de bem. (P2 - 60 anos - E.E. Batista Neves, 2019)

Cidadania é ter direito à educação, saúde, moradia, trabalho, ouvir e ser ouvido. Poder também não votar, seria um direito do cidadão. (P6 - 71 anos - E.E. Batista Neves, 2019)

Em uma faixa etária de 18 até 71 anos, $60 \%$ os alunos entrevistados concordaram que os conteúdos influenciam diretamente na sua formação/participação política e social, incentivando-os ao engajamento nas ações comunitárias, enquanto $40 \%$ não estabelecem correlações do aprendizado com a sua postura e formação política/social.

Gráfico 2 - Relação dos estudos com a participação política e social Escola Batista Neves

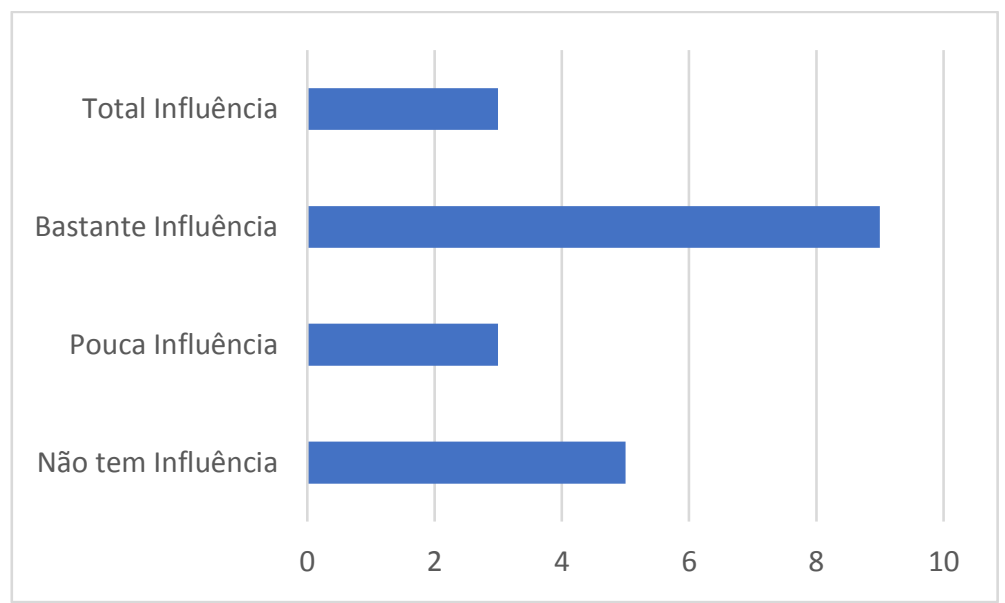

Fonte: Elaborado pelos pesquisadores

Os relatos e dados iniciais representam a explicação de Freire sobre a política ser resultado de um processo de conscientização do indivíduo, imbricada no desenvolvimento 
educacional dos estudantes, possibilitando a estes (através de uma educação problematizadora por parte do docente) o engajamento nas discussões políticas e sociais que afetam a sua vida, sendo "[...] investigadores críticos, em diálogo com o educador, investigador crítico também" (FREIRE, 2019, p. 80).

Observamos que $90 \%$ dos alunos relataram o impacto positivo que a EJA proporciona nas suas relações familiares (e somente 10\% não citaram em suas falas se proporcionou alguma mudança benéfica no âmbito familiar) e $60 \%$ dos sujeitos entrevistados afirmaram que os aprendizados obtidos influenciam nas suas tomadas de decisão enquanto sujeito social (enquanto $40 \%$, apesar de concordar com a importância que a escola incide sobre a sua formação cidadã, considera que este processo ainda não se concretiza na sua práxis), demonstrando que a correlação dos estudos com o reconhecimento de serem cidadãos tem impactado na autoestima e na valoração da educação como uma mudança de vida, afirmada pelos próprios estudantes:

Bastante! Aprendi a falar melhor, a escolher o que é bom e não ter medo de caras e bocas. (P6 - 71 anos - E.E. Batista Neves, 2019)

Me ajuda ainda mais, pois descobri que sou capaz de ir mais longe em busca do meu sonho. Todos os professores me inspiram e minha diretora Cristina é sem dúvida minha base. Sem estudo não sou ninguém, com estudo sou quem eu quiser. (P10 - 36 anos - E.E. Batista Neves, 2019)

No processo de triangulação de dados foi possível constatarmos um outro cenário durante a análise das respostas à última questão: apesar de obtermos os mesmos resultados, as escolhas dos três aspectos mais importantes da EJA, diferentemente da primeira escola, as três respostas ancoram no perfil dos alunos de que ocupam esses espaços visando reivindicar na sociedade o protagonismo e a participação como cidadão.

$\mathrm{O}$ resultado diametralmente oposto entre as duas escolas abre um leque para uma investigação mais minuciosa (principalmente no primeiro caso), observando também os docentes, a gestão e a importância da escola para a comunidade, mas, sobre a temática estudada, percebe-se no primeiro caso que as práticas pedagógicas não proporcionam aos alunos a experiência de uma educação dialógica, correlacionando os conteúdos didáticos com as suas vivências, sendo que Paulo Freire (2019, p. 94) disserta sobre isso em sua obra, conforme observa-se a seguir:

A educação que se impõe aos que verdadeiramente se comprometem com a libertação não pode fundar-se numa compreensão dos homens como seres "vazios" a quem o mundo "encha" de conteúdos; não pode basear-se numa consciência especializada, mecanicistamente compartimentada, mas nos homens como "corpos conscientes" e na consciência como consciência 
intencionada ao mundo. Não pode ser a do depósito de conteúdos, mas a da problematização dos homens em suas relações com o mundo.

É possível também confirmar a importância de trazer para a sala de aula os tensionamentos da comunidade, pois a escola é o lócus de formação e uma instituição que representa a comunidade, fazendo parte da dinâmica social do bairro, pois a não fomentação sobre o que é e como é a participação social desses indivíduos na cidade dentro das ações escolares corrobora com a construção brasileira do "Não-Cidadão" que Santos (2014, p. 25, grifo do autor)identificou, dissertando que:

Em nenhum outro país foram assim contemporâneos e concomitantes processos como [...] a degradação das escolas, a instalação de um regime repressivo com a supressão dos direitos elementares dos indivíduos, [...] o triunfo, ainda que superficial, de uma filosofia de vida que privilegia os meios materiais e se despreocupa com os aspectos finalistas da existência e entroniza o egoísmo como lei superior, porque é o instrumento da buscada ascensão social. Em lugar do cidadão formou-se um consumidor, que aceita ser chamado de usuário.

Os resultados obtidos neste estudo de caso demonstram que, apesar de importante, a Base Nacional Comum Curricular e a Política de EJA da Rede Estadual do Estado da Bahia, as quais traçam diretrizes nos conteúdos e nas práticas pedagógicas de ensino/aprendizagem, não garantem com sua aplicação os mesmos resultados, sobretudo referentes à temática a qual estudamos. O entendimento da escola como uma representatividade física da educação e da comunidade possibilita trabalhar as questões que afetam o dia a dia dos estudantes, e a estimulação da criticidade enquanto sujeitos sociais se dá justamente quando uma metodologia de ensino promove a triangulação do conteúdo didático com as problematizações sociais e o sujeito aprendente, auxiliando-o no seu desenvolvimento formativo e cidadão, conforme vemos na resposta de um dos alunos entrevistados: "Melhorou o meu convívio social e me deu uma visão diferente perante as coisas que particularmente não dava importância, como o que é ser cidadão e qual o papel de um cidadão". (P5 - 20 anos - E.E. Batista Neves, 2019)

Desse modo, observamos no estudo realizado que as anotações de Bakhtin (2017) e Vygotsky (2015) sobre a multiplicidade de vozes que o sujeito constrói durante sua trajetória de vida e como as interações das relações sociais influenciam no processo de desenvolvimento mental e humano, respectivamente, evidenciam que a cidadania dentro do espaço escolar deve ser pensada e fundamentada em toda ação (pedagogicamente e administrativamente), pois a EJA não deve ter somente a difusão do saber como processo de reparação aos sujeitos vinculados a ela, mas também deve promover concomitantemente ao processo de 
ensino/aprendizagem o senso crítico e a valoração do papel que o aluno tem na mudança da sociedade enquanto cidadão.

\section{Considerações finais}

Este artigo foi realizado com o objetivo primaz de analisar como as práticas pedagógicas na EJA colaboram positivamente na construção do sujeito social em seus alunos e na formação cidadã, sendo que os estudos de caso realizados nas Escolas Estaduais Professor Nelson Barros e Batista Neves evidenciaram ainda mais a relevância com a ação docente para o aprendizado dos alunos ao seu exercício enquanto cidadãos.

É observado também que a escola, enquanto espaço do cidadão, deve promover entre todos os sujeitos a cidadania na práxis, pois conforme citado anteriormente, apesar de ser uma conquista individual, a cidadania se desenvolve dentro das relações coletivas, e a proposta de uma educação pautada na dialética e na valoração dos indivíduos, conforme a proposta de Paulo Freire, deve nortear o modus operandi do ensino/aprendizagem do professor dentro da sala de aula, mas também deve fazer parte das relações interpessoais entre os alunos e profissionais dentro das escolas.

No que tange ao estudo de caso realizado, observamos durante o processo em campo e também no desenvolvimento deste artigo, que se faz necessária uma prática pedagógica que considere a regionalidade dos sujeitos na ação de ensino/aprendizagem, uma vez que a escola representa o espaço de ensino, mas também é a referência comunitária na qual "pensar sobre ser cidadão" é imprescindível para a construção de um sujeito social, pois mesmo que a BNCC e a Política de EJA determinem as ações dos professores e gestores, cada instituição representa exclusivamente a comunidade em que está situada e traz para si os seus sujeitos, com as suas demandas, dificuldades e esperanças.

Sobre a EJA, por fim, apesar de simbolicamente ser uma modalidade de resgate e reparação dos direitos para as pessoas que ao decorrer da sua vida tiveram a educação violada e suprimida, ela precisa dentro dos seus espaços fazer jus ao que representa, com professores e técnicos que tenham um olhar mais amplo, não enxergando somente o aspecto estudantil dos alunos, mas que neles há também as problemáticas familiares, socio-históricas, e que a ação docente e escolar precisar lidar com isso, pois para além do espaço de educação, a escola é o espaço da comunidade, um espaço de cidadania. 


\section{REFERÊNCIAS}

BAHIA. CONDER. Companhia de Desenvolvimento Urbano do Estado da Bahia. Painel de informações: dados socioeconômicos do município de Salvador por bairros e prefeiturasbairro /Sistema de Informações Geográficas Urbanas do Estado da Bahia. 5. ed. Salvador: CONDER/INFORMS, 2016. 189 p.

BAKHTIN, M. M.; VOLOSHINOV, V. N. Marxismo e filosofia da linguagem: problemas fundamentais do método sociológico na ciência da linguagem. São Paulo: Editora 34, 2017. $376 \mathrm{p}$.

BRASIL. Constituição (1988). Constituição da República Federativa do Brasil. Brasília, DF: Senado Federal: Centro Gráfico, 2017.947 p.

CARTA CAPITAL EDITORIAL (Brasil) (Ed.). “Os trabalhadores querem menos direitos e mais trabalho", diz Bolsonaro. Carta Capital. São Paulo. 25 out. 2019. Disponível em: https://www.cartacapital.com.br/politica/os-trabalhadores-querem-menos-direitos-e-maistrabalho-diz-bolsonaro/. Acesso em: 28 dez. 2019.

FLICK, U. Introdução à pesquisa qualitativa. 3. ed. Trad. Joice Elias Costa. Porto Alegre: Artmed, 2017. 408 p.

FREIRE, P. Pedagogia da autonomia: saberes necessários à prática educativa. 1. ed. São Paulo: Paz e Terra, 2019. 144 p.

FREIRE, P. Pedagogia do oprimido. 1. ed. São Paulo: Paz e Terra, 2019. 256 p.

GIL, A. C. Como elaborar projetos de pesquisa. 5. ed. São Paulo: Atlas 2010.

GIL, A. C. Métodos e técnicas de pesquisa social. 7. ed. São Paulo: Atlas, 2019.

HOUAISS, A. Pequeno dicionário Houaiss da língua portuguesa. São Paulo: Moderna, 2015. $1176 \mathrm{p}$.

MARCONI, M. A.; LAKATOS, E. M. Técnicas de pesquisa: planejamento e execução de pesquisa, amostragens e técnicas de pesquisa, elaboração, análise e interpretação dos dados. 8 . ed. São Paulo: Atlas, 2017. 328 p.

MINAYO, M. C.; DESLANDES, S. F.; GOMES, R. (Org.). Pesquisa social: teoria, método e criatividade. 1. ed. Petrópolis: Vozes, 2016. 96 p.

SANTOS, M. A. O espaço do cidadão.7. ed. São Paulo: Edusp, 2014. 176 p.

SÃO PAULO. "A EJA não tem lugar no MEC atualmente”, afirma Sonia Couto. De Olho nos Planos, 2019. Disponível em: http://www.deolhonosplanos.org.br/100-dias-de-bolsonaro-eja/. Acesso em: 20 out. 2019.

TRIVIÑOS, A. N. S. Introdução à pesquisa em ciências sociais: a pesquisa qualitativa em educação. 5. ed. São Paulo: Atlas, 2009. 176 p. 
VYGOTSKY, L. S. A formação social da mente. 7. ed. São Paulo: Martins Fontes, 2015. $224 \mathrm{p}$.

YIN, R. Estudo de caso: planejamento e métodos. 5. ed. Porto Alegre: Bookman, 2014. 320 p.

\section{Como referenciar este artigo}

SOUZA, F. P.; MATTA, A. E. R.; AMORIM, A. A Educação de Jovens e Adultos pautada na cidadania e na construção do sujeito social: um estudo de caso nas escolas estaduais Professor Nelson Barros e Batista Neves. Revista Ibero-Americana de Estudos em Educação, Araraquara, v. 16, n. 2, p. 703-719, abr./jun. 2021. e-ISSN: 1982-5587. DOI: https://doi.org/10.21723/riaee.v16i2.13604

Submetido em: $27 / 04 / 2020$

Revisões requeridas em: 11/07/2020

Aprovado em: 10/11/2020

Publicado em: 01/02/2021 